\title{
COMMENTARY
}

\section{An Integrated Framework for Achieving Sustainable Development Goals Around the World}

Jianguo Liu *

\section{INTRODUCTION}

One of the biggest global challenges is to achieve the United Nations' Sustainable Development Goals (SDGs), agreed upon by 193 countries in 2015. Many institutions and scholars have called for creating and synthesising knowledge for meeting the 17 ambitious goals (e.g., no poverty, zero hunger, biodiversity conservation, climate mitigation). Some studies recognise synergies and trade-offs among the goals within a place (International Council for Science 2017), but little attention has been paid to SDG interrelationships among different places (Liu 2017).

The United Nations states that SDGs should be achieved around the world. For example, SDG 1 aims 'to end poverty in all forms everywhere'. At present, the scores of SDGs are vastly different among countries (Sachs $e t$ al. 2017). For instance, the scores of SDG 2 (Zero hunger - 'End hunger, achieve food security and improved nutrition and promote sustainable agriculture') range from 22 (Yemen) to 86 (Sweden) (Figure 1). The vast majority of countries in Africa (e.g., Sudan, Chad, and Niger) are among those with the lowest scores, together with some Asian countries (e.g., India, Pakistan, Sri Lanka) and Latin American countries (e.g., El Salvador, Guatemala, Honduras). Japan, the US, and western European countries are among those with the highest scores on SDG 2.

To achieve SDGs around the world, an integrated framework is required and many fundamental questions need to be answered. For instance, how can the SDGs be achieved everywhere? How do efforts for achieving the

\footnotetext{
* Center for Systems Integration and Sustainability, Department of Fisheries and Wildlife, Michigan State University, East Lansing, MI 48823, USA; liuji@msu.edu.

Copyright (C) Liu 2018. Released under Creative Commons Attribution-NonCommercial 4.0 International licence (CC BY-NC 4.0) by the author.

Published by Indian Society for Ecological Economics (INSEE), c/o Institute of Economic Growth, University Enclave, North Campus, Delhi 110007.
}

ISSN: 2581-6152 (print); 2581-6101 (web).

DOI: https://doi.org/10.37773/ees.v1i2.32 
goals in one place offset or enhance goal-achieving efforts in other places? I first introduce the metacoupling framework and then apply the framework to illustrate the realisation of SDG 2 .

Figure 1. Scores of SDG 2 (Zero hunger - 'End hunger, achieve food security and improved nutrition and promote sustainable agriculture')

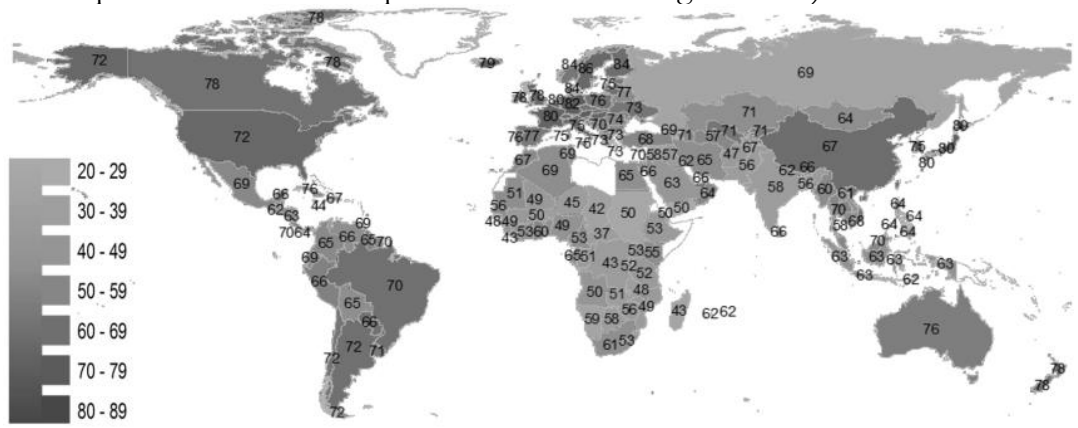

Data source: Sachs et al. (2017).

\section{METACOUPLING FRAMEWORK}

The new integrated framework of metacoupling (human-nature interactions within as well between adjacent and distant places or systems; Liu 2017) can help address the questions raised above. Human-nature interactions shape all SDGs. The metacoupling framework builds on and expands research on coupled human and natural systems in which human and natural components interact with each other (Liu et al. 2007).

Previous research efforts on coupled human and natural systems have generated some useful insights, but they typically concentrate on individual places (e.g., cities) (Kramer et al. 2018). While some studies have indicated that human actions (e.g., timber harvesting and manufacturing) in one place can affect human well-being and the environment in other places through trade and emissions of pollutants and greenhouse gases (GHG) (Lambin and Meyfroidt 2011; DeFries et al. 2010), they do not address SDGs explicitly.

The metacoupling framework encompasses not only human-nature interactions within a system (intracoupling) or place (e.g., country, state, city, county) but also interactions between adjacent systems (pericoupling) and between distant systems (telecoupling). Intracoupling may include timber harvesting and farming in a specific place. There are many types of pericouplings and telecouplings, such as trade, migration, species invasion, foreign investment, technology transfer, knowledge transfer, and tourism. 
Furthermore, there are interactions among intracoupling, pericoupling, and telecoupling (Liu 2017).

The metacoupling framework consists of five interrelated components (systems, flows, agents, causes, and effects). A metacoupled system includes two or more coupled human and natural systems linked through flows (e.g., movement of matter, energy, information, capital, water, organisms, and people). Agents (e.g., farmers, traders, animals) are decision-making entities that boost or impede various flows. Causes are reasons (e.g., ecological, hydrological, geological, socio-economic, political, cultural factors) behind a metacoupling that produces various effects (e.g., ecological, hydrological, biogeochemical, biological, socio-economic).

\section{APPLYING THE METACOUPLING FRAMEWORK TO SDGS}

The metacoupling framework can help organise and coordinate efforts to achieve SDGs within a specific place as well as between adjacent and distant places. For example, to eliminate hunger across the world (SDG 2), under the metacoupling framework one needs to consider human-nature interactions not only within a country at the national level but also relationships between the focal country and adjacent and distant countries. Factors within the country may include food production and food demand. Food demand is a function of per capita food consumption and population size. Food production is influenced by many factors, such as available arable land, yield, labour, fertilisers, pesticides, water, crop varieties, policies, and harvest management. Crop varieties largely determine food nutrients, while the use of agrochemicals such as pesticides and herbicides affects food safety. The costs of production may vary among contexts that have different conditions.

Regarding relationships between the focal country and other countries for achieving SDG 2, food trade and associated factors need to be considered. While food security has many dimensions, food quantity is fundamentally important. Given the space limitation, this commentary focuses on food quantity. The quantity of food and related products traded (flows) depend on supply, affordability, demand, and relevant policies (causes). For importing countries, the affordability of importing food is affected by food price and expandable income. For exporting countries, the supply or availability of food is influenced by food production, infrastructure of transporting food from production areas to export ports, political stability, and other related factors. Of course, trade policy and diplomatic relationships between trade partners influence the amount and timing of food trade. Many agents are involved, such as producers, traders, 
policymakers, and consumers. As to effects of trade, the distances between importing and exporting countries may affect the economic and environmental costs (e.g., GHG emissions) of transporting food and the risk of food supply reliability. Generally speaking, the more distant the trade partners, the higher the cost in transportation. Trade between partners also generates spillover effects by affecting trade with other countries and emitting GHGs that drive global climate change.

All countries produce food domestically as well as import and export food; however, net imports or exports vary drastically with four general patterns. One, many countries with low scores of SDG 2 (Figure 1) import more than export (Food and Agriculture Organization 2018). For example, Yemen, which has the lowest score on SDG 2, imported 64 million tons of food over 2000-2013. Russia and Saudi Arabia imported even more food than Yemen during that period although they have somewhat higher scores for SDG 2.

Second, some countries with low scores on SDG 2, such as India and Guatemala, export more than import. During 2000-2013, India and Guatemala ranked $11^{\text {th }}$ and $17^{\text {th }}$ in net exports. At first glance, this may not make sense. However, these countries may rely on food exports to earn foreign cash or exchange for other goods and products even at the risk of exacerbating domestic food insecurity. This also demonstrates the complexity of achieving different SDGs simultaneously.

Third, some countries with the highest scores of SDG 2 import the largest amounts of food in the world. For example, Japan ranked first in total net food imports during 2000-2013 even though its SDG 2 scores are among the highest. In fact, among the top net importers, seven countries (Republic of Korea, UK, Belgium, Germany, the Netherlands, and Italy, in addition to Japan) are in the top 20 highest scores for SDG 2, including the top two (Belgium and Republic of Korea). Finally, some countries with high scores of SDG 2 export the largest amounts of food, such as the US, Brazil, Australia, Canada, and France.

Thus, for food security, it is not just a matter of either producing enough food domestically or importing food. Each strategy may have different costs associated with flows of energy and materials. As many as 66 countries are not self-sufficient under water and land constraints alone (Fader et al. 2013). It is common to import materials and capital to produce more food domestically. For example, in Brazil, most of the fertilisers used for food production are imported from other countries. In 2016, Brazil imported nearly 25 million tons (or 73 per cent) of the fertilisers for domestic agricultural production (Brazilian National Fertiliser Association 2017). Of that, about 90 per cent of the potassium-rich fertiliser was 
imported from distant countries such as Canada, Belarus, Russia, and Germany (Foreign Trade and Services 2017). On the other hand, some countries such as the US and France achieve food self-sufficiency without imports (Fader et al. 2013). However, such self-sufficiency requires sufficient land, water, nutrients, etc. There are trade-offs with both financial and environmental costs of using resources within a country versus importing materials from other countries nearby or far away.

Food production and demand also differ within a country. For example, many rural areas can produce food for self-sufficiency, but cities usually solely or mainly depend on food produced elsewhere. Even an increase in urban agriculture does not produce enough food to meet the consumption demand of city residents (Badami and Ramankutty 2015). Thus, to meet food demand among different areas, substantial food movement within a country is also needed.

The example above focuses on applying the metacoupling framework to achieve SDG 2, but general approaches are applicable to address other SDGs and interactions among SDGs. For instance, for SDG 14 (life under water), it is important to protect not only water bodies such as oceans, but also terrestrial systems nearby and far away, because fertilisers and pesticides for meeting SDG 2 from terrestrial systems can flow into aquatic systems (Zeng et al. 2015), thus compromising SDG 14 and other SDGs.

\section{CONCLUDING REMARKS}

The metacoupling framework lays a good conceptual foundation to help achieve SDGs around the world. To turn the conceptualisation into reality, researchers in different places need to go beyond the traditional place-based and comparative studies. It is crucial to trace and integrate flows of people, information, goods, products, capital, energy, matter, and other entities such as organisms among different places. Paradigm shifts from scattered and separate research to systematic and integrated research can help transform sustainability science and generate novel insights for understanding complex SDG relationships within as well as between adjacent and distant places. Such new sustainability science is essential for developing effective policies and governance for realising intertwined SDGs across local to global scales. 


\section{ACKNOWLEDGEMENTS}

I would like to thank Sue Nichols and Nandan Nawn for their helpful edits, Shuxin Li for drawing Figure 1, and the US National Science Foundation and Michigan AgBioResearch for funding.

\section{REFERENCES}

Badami, Madhav G. and Navin Ramankutty. 2015. "Urban agriculture and food security: A critique based on an assessment of urban land constraints." Global Food Security 4: 8-15. https://doi.org/10.1016/j.gfs.2014.10.003

Brazilian National Fertiliser Association (Associação Nacional Para Difusão de Adubos). 2017. Principais indicadores do setor de fertilizantes 2017 (Main indicators of the fertilisers market 2017).

http://www.anda.org.br/estatistica/Principais Indicadores 2016.pdf

DeFries, Ruth S., Maria Uriarte, Thomas Rudel, and Mathew Hansen. 2010. "Deforestation driven by urban population growth and agricultural trade in the twenty-first century." Nature Geoscience 3 (3): 178-81.

https://doi.org/10.1038/ngeo756

Fader, Marianela, Dieter Gerten, Michael Krause, Wolfgang Lucht, and Wolfgang Cramer. 2013. "Spatial decoupling of agricultural production and consumption: Quantifying dependences of countries on food imports due to domestic land and water constraints." Environmental Research Letters 8 (1): 014046.

https://doi.org/10.1088/1748-9326/8/1/014046

Food and Agriculture Organization (FAO). 2018. Food and agriculture data (FAOSTAT). http://www.fao.org/faostat/en/\#home

Foreign Trade and Services (Ministério da Indústria, CEeSMoI). 2017. Balança dos países 2015 [Countries' balance of trade 2015].

http://www.mdic.gov.br/index.php/comercio-exterior/estatisticas-decomercioexterior/balanca-comercial-brasileira-mensal-2?layout $=$ edit\&id $=1210$

International Council for Science. 2017. A Guide to SDG Interactions: from Science to Implementation. Paris: International Council for Science. https://www.icsu.org/cms/2017/05/SDGs-Guide-to-Interactions.pdf

Kramer, Daniel, Joel Hartter, Angela Boag, Meha Jain, Kara Stevens, Kimberly Nicholas, William McConnell, et al. 2017. "Top 40 Questions in Coupled Human and Natural Systems (CHANS) Research.” Ecology and Society 22 (2): 44. https://doi.org/10.5751/ES-09429-220244

Lambin, Eric F. and Patrick Meyfroidt. 1 Mar, 2011. "Global land use change, economic globalization, and the looming land scarcity." Proceedings of the National Academy of Sciences of the United States of America 108 (9): 3465-72. https://doi.org/10.1073/pnas.1100480108 
Liu, Jianguo. 2017. "Integration across a metacoupled world." Ecology and Society 22 (4): 29. https://doi.org/10.5751/ES-09830-220429

Liu, Jianguo, Thomas Dietz, Stephen R Carpenter, Marina Alberti, Carl Folke, Emilio Moran, Alice N Pell, et al. 2007. "Complexity of coupled human and natural systems.” Science 317 (5844): 1513-16. https://doi.org/10.1126/science.1144004

Sachs, J., G. Schmidt-Traub, C. Kroll, D. Durand-Delacre, and K. Teksoz. 2017. SDG index and dashboards report 2017. New York: Bertelsmann Stiftung and Sustainable Development Solutions Network (SDSN).

http://www.sdgindex.org/assets/files/2017/2017-SDG-Index-and-DashboardsReport--full.pdf

United Nations Department and Social Affairs. nd. Sustainable Development Knowledge Platform. https://sustainabledevelopment.un.org/sdgs

Zeng, Xiangfeng, Xijuan Chen, and Jie Zhuang. 2015. “The positive relationship between ocean acidification and pollution.” Marine Pollution Bulletin 91 (1): 14-21. https://doi.org/10.1016/j.marpolbul.2014.12.001 